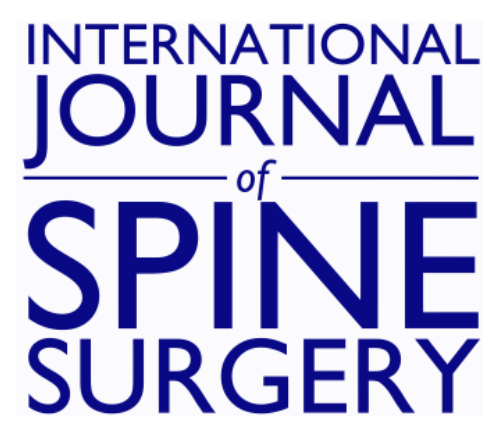

\title{
Idiopathic Early-Onset Scoliosis Treated With Magec Rods: What to Do After the Lengthening Period Is Over?
}

MASSIMO BALSANO and MAURO SPINA

Int J Spine Surg 2020, 14 (5) 847-851

doi: https://doi.org/10.14444/7094

http://ijssurgery.com/content/14/5/847

This information is current as of April 26, 2023.

Email Alerts Receive free email-alerts when new articles cite this article. Sign up at:

http://ijssurgery.com/alerts 


\title{
Idiopathic Early-Onset Scoliosis Treated With Magec Rods: What to Do After the Lengthening Period Is Over?
}

\author{
MASSIMO BALSANO, MD, MAURO SPINA, MD \\ Department of Orthopedics and Traumatology, Azienda Ospedaliera Universitaria Integrata of Verona, Verona, Italy
}

\begin{abstract}
The treatment of early-onset scoliosis with magnetic growing rods has been established, but the management at the end of the lengthening program is still controversial. The options available are removal of rods and observation, removal of rods and immediate fusion, or replacement/maintenance of rods. We present 2 cases of early-onset scoliosis patients treated with Magec rods, up to skeletal maturity. In the first case of a Lenke 3 scoliosis (14 years and 11 months) with a thoracic curve of $50^{\circ}$ and lumbar curve of $40^{\circ}$, we removed the rods and kept the patient under observation. After 5 months, the patient showed curve progression, with a thoracic curve of $61^{\circ}$ and a lumbar curve of $57^{\circ}$. Consequently, we performed an instrumented T4 to L4 fusion with a correction of the thoracic curve of $66 \%$ and lumbar curve of $60 \%$. In the second case of a Lenke 1 scoliosis (15 years and 10 months) with a thoracic curve of $38^{\circ}$, the rods were removed and the patient was kept under observation. After 10 months, following a curve progression, presenting a thoracic curve of $72^{\circ}$, we performed an instrumented fusion T5 to L2 and right thoracoplasty $\left(6^{\text {th }}\right.$ to $11^{\text {th }}$ ribs) with a $40 \%$ curve correction. Observing these 2 cases at the end of the treatment with Magec rods, even in case of a good and satisfying final correction, skeletal maturity, and secondary sexual characteristics, we recommend immediate instrumented spine fusion.
\end{abstract}

Other \& Special Categories

Keywords: early-onset scoliosis, magnetic growing rods, rods' removal, spontaneous spine autofusion, skeletal maturity, immediate instrumented fusion

\section{INTRODUCTION}

Early-onset scoliosis (EOS) is a spinal deformity in children ages 10 years or younger, with idiopathic, neuromuscular, congenital, and syndromic etiology. Untreated EOS patients show a high risk of thoracic insufficiency, impaired cardiopulmonary function, and early mortality rates. ${ }^{1}$ Additionally, early spinal fusion, before lung maturity, is associated with a significant morbidity due to respiratory complications. ${ }^{2}$ The development of modern surgical techniques based on guided growth, vertebral compression, or distraction-based implants has intended to avoid these dramatic consequences. EOS treatment with Magec rods has been established, but patient management at the end of the lengthening period, until skeletal maturity, remains controversial. In the literature, the reported options ${ }^{3}$ are the rods' removal followed by patient observation, rods' removal and immediate instrumented fusion, or rod maintenance/replacement. We present 2 cases of EOS patients treated with Magec rods (NuVasive Specialized Orthopedics Inc, Aliso Viejo,
CA) up to skeletal maturity. After the complete lengthening, the authors decided to remove the rods and keep the patient under observation because we observed a good correction of scoliosis, the complete Risser and the appearance of secondary sexual characteristics at the end of treatment with rods. Data for this investigation were collected and analyzed in compliance with the procedures and policies set forth by the Helsinki Declaration, and the parents of 2 patients gave their informed consent to data treatment.

\section{CASE REPORTS}

The first patient, a girl who came to our observation at the age of 10 years with a Lenke 3 scoliosis right thoracic $34^{\circ}$ and left lumbar $43^{\circ}$, for which we implanted 2 Magec rods (size 5.5-mm standard rod on the right and offset rod on the left, actuator $90 \mathrm{~mm}$ ) anchored with pedicle screws in T3 to T4 and L3 to L4. After periodic distractions (1 mm every 3 months), we removed the rods at the age of 14 years and 11 months, with a final right 


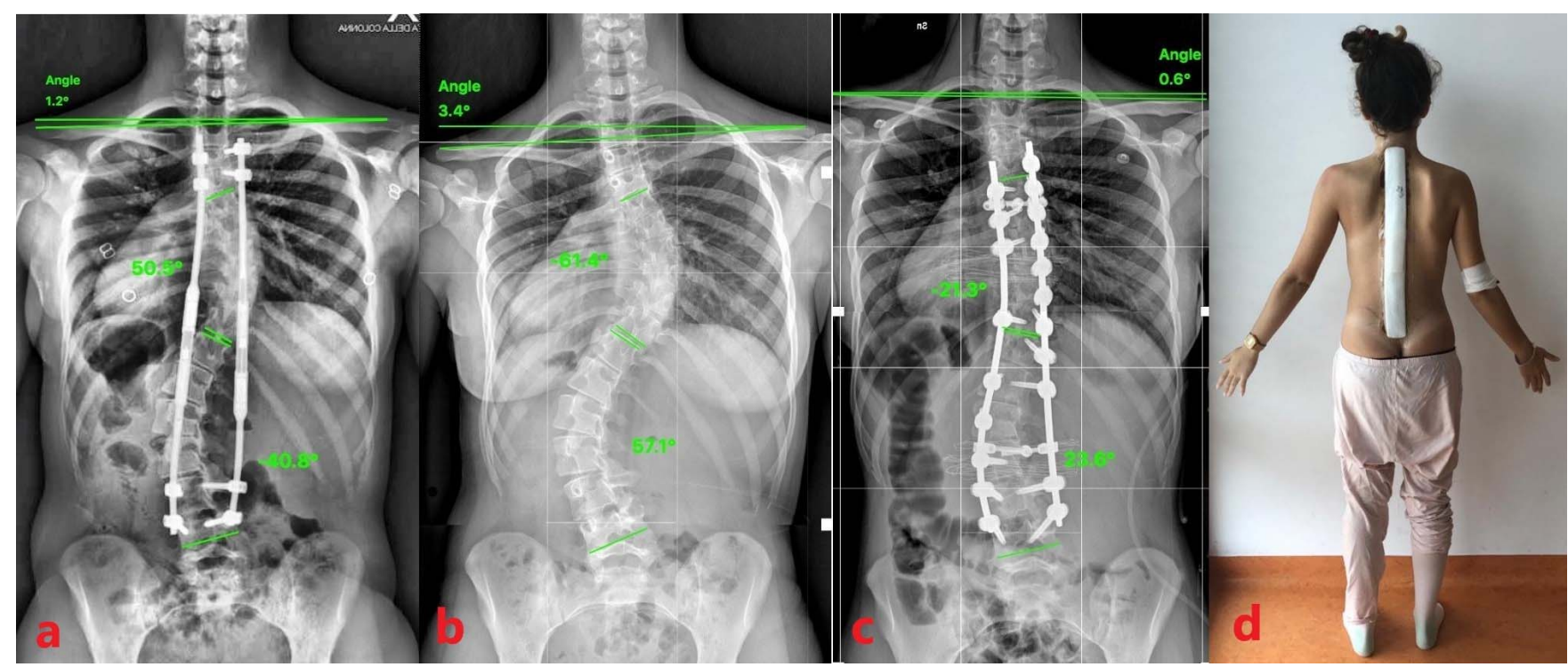

Figure 1. $1^{\circ}$ case. a) At age 14 years and 11 months, the final distraction of the Magec rods was reached; the radiologic image shows a right thoracic curve of $50^{\circ}$ and a left lumbar curve of $40^{\circ}$ (Risser 5). b) Five months after removal of Magec rods, the radiologic image shows the curves worsening, with a right thoracic curve of $61^{\circ}$ and a left lumbar curve of $57^{\circ}$. c) The radiologic image shows an instrumented fusion T4 to L4 with a right thoracic curve of $21^{\circ}$ and left lumbar curve of $23^{\circ}$. d) The clinical image shows the excellent final results.

thoracic curve of $50^{\circ}$ and left lumbar of $40^{\circ}$ (Risser 5). Periodic radiographic follow-ups showed both curves' progressions and a shortening of the trunk. Therefore, 5 months after the rods' removal, starting from a right thoracic $61^{\circ}$ curve and a left L $57^{\circ}$ curve, we performed a final instrumented fusion T4 to L4. Given the good flexibility of the curve, we obtained an excellent clinical and radiographic results, with a final correction of the thoracic curve of $66 \%$ and the lumbar curve of $60 \%$ (Figure 1).

The second patient is a girl who came to our observation at the age of 10 and a half years, with a Lenke 1 scoliosis right thoracic of $45^{\circ}$. In this case we implanted 2 Magec rods (size 5.5-mm standard rod on the left and offset rod on the right, $90-\mathrm{mm}$ actuator) anchored with hooks in T4 to T5 and pedicle screws in L3 to L4. After periodic distractions, we removed the rods at the age of 15 years and 10 months with a right thoracic curve of $38^{\circ}$ (Risser 5). Periodic radiographic controls showed both a progressive and severe progression of the curve, with an evident rib hump and significant shoulder malalignment. Therefore, 10 months after the rods' removal, starting from a right thoracic curve of $72^{\circ}$, we performed a T5 to L2 final instrumented fusion (Figure 2). In this second case, because of the rigidity of the curve, due to a spontaneous fusion in the convexity of the curve, an important rib hump (Figure 3), and to improve the aesthetic result, we decided to associate a right thoracoplasty at the apex of the ribs' deformity (from the 6th to the 11th rib), but resulting in a subsequent pleural effusion. The clinical and radiographic final results were good, with a correction of the right thoracic curve of $40 \%$ and well-balanced spine (Figure 2, c and d).

\section{DISCUSSION}

Since their introduction, the growing rods have been an effective and safe method to control progressive and severe deformity in a young child, until the trunk reaches an adequate height, while preserving the implicit intention of performing the final fusion. In 2010, Cahill et al ${ }^{4}$ demonstrated high rates $(89 \%)$ of spontaneous autofusion in patients with immature spines who were treated with growing rods. Therefore, the authors considered the final fusion, when in the presence of skeletal maturity and good correction, to be unnecessary. The final instrumented fusion, after distractionbased devices, is associated with high complication rates. $^{5,6}$ In 2017 Kocyigit et $\mathrm{al}^{3}$ mentioned a comparative study in patients treated with growing rods, and they concluded that in patients who achieved skeletal maturity, rod removal without new instrumentation is an unacceptable treatment because it leads to a worsening of the deformity. The results in the 2 presented cases confirm the 


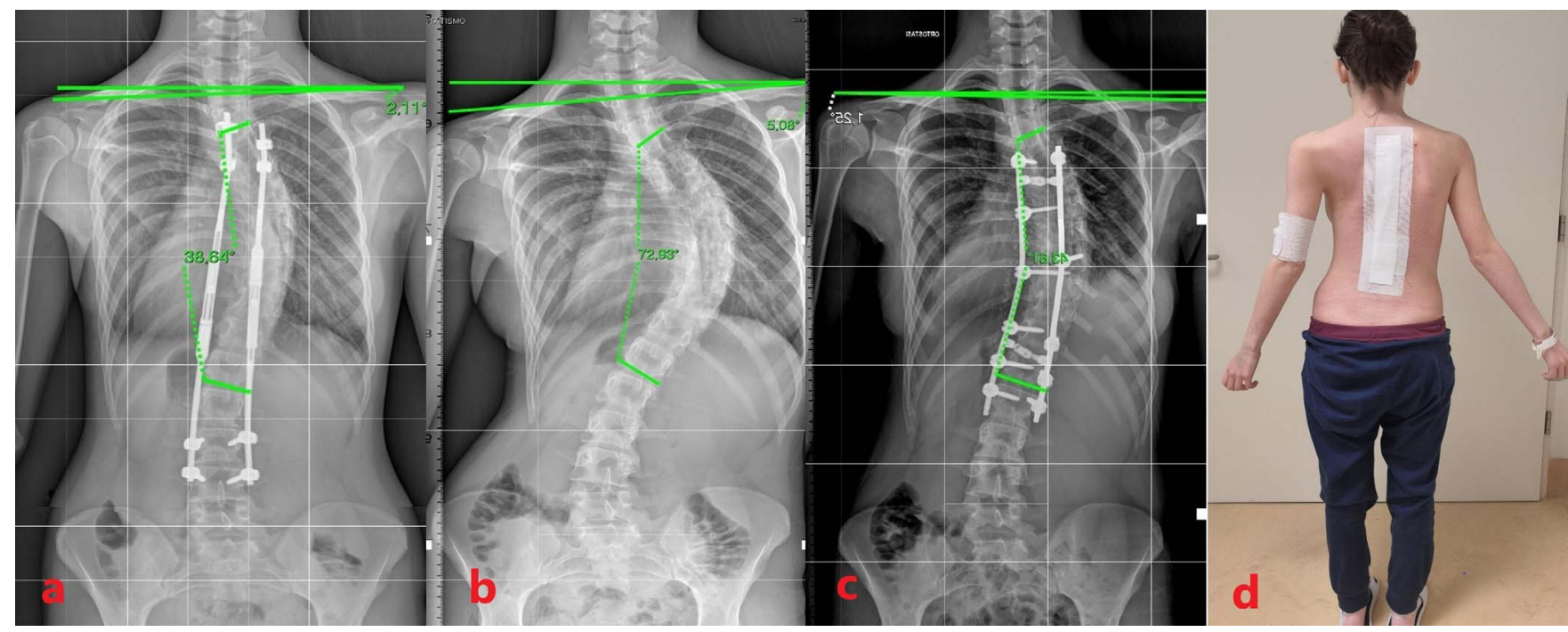

Figure 2. $2^{\circ}$ case. a) At age 15 years and 10 months, the final distraction of the Magec rods was reached; the radiologic image shows a right thoracic curve of $38^{\circ}$ (Risser 5). b) Ten months after removal of the Magec rods, the radiologic image shows the curve's evolution, with a right thoracic curve of $72^{\circ}$. c) The radiologic image shows an instrumented fusion T5 to L2 with a right thoracic curve of $43^{\circ}$ and right thoracoplasty $\left(6^{\circ}-11^{\circ}\right.$ ribs). d) The clinical image shows the good final results.

conclusions of Kocygit et al. ${ }^{3}$ Despite observing, after the rods' removal, an acceptable and satisfying final correction $\left(\leq 50^{\circ}\right)$, skeletal maturity (Risser 5), and the appearance of secondary sexual characteristics, we also observed a rapid progression of the deformity. Because of this experience, some observations are needed.

The Risser test may not be entirely reliable for evaluating the potential for further skeletal growth. Minkara et $\mathrm{al}^{7}$ believe that the Sanders classification should be used to guide treatment options in patients with Adolescent Idiopathic Scoliosis because Risser staging results in mistreatment in a total of 1 of 4 patients compared with the Sanders classification.

Spontaneous autofusion after rod removal cannot be a realistic parameter to be taken into consideration for the decision of the subsequent treatment. Jain et $\mathrm{al}^{8}$ outlined several important considerations regarding the quality of the autofusion after growing-rod treatment in EOS: first, it may be incomplete, with some immobile segments and others with some preserved mobility; second, the autofusion mass may be thin; and third, the durability of this autofusion mass is unknown.

The decision to perform spinal fusion at the end of distraction-based treatment is complex and multifactorial, based on patient history and features, family, and surgeon-specific factors. ${ }^{6}$ In fact, in the first case presented, the choice of final fusion was influenced not only by the progression of the deformity, but mostly by the insistence of the girl and her family members, who did not accept the final aesthetic result. Regarding the second case presented, the choice of final fusion was influenced by the rapid and severe increase in the thoracic curve of about $50 \%$, with an unacceptable aesthetic appearance caused by an important rib hump and trunk imbalance (Figure 3, a and b).

Lastly, the timing of the final instrumented fusion is very important. We observed that the more time that had passed since the rods removal, the more the complex and invasive posterior instrumented resulted, with a consequently less satisfactory final result. In fact, in the second case, 10 months after the rods' removal, the curve had an important thoracic rotation; it was rigid (Figure 3) and required additional thoracoplasty surgical time, with subsequent pleural effusion as a complication.

Because of our limited experience, for those EOS patients treated with distraction devices, when skeletal maturity has been reached, we strongly recommend immediate final instrumented fusion when the growing rods are removed. The "watchful waiting" alternative, leaving the rods in place, could be an option, but currently the risk of complications from long-term observation, such as implant pain or failure, or curve progression, and late infection, still remains unknown. 


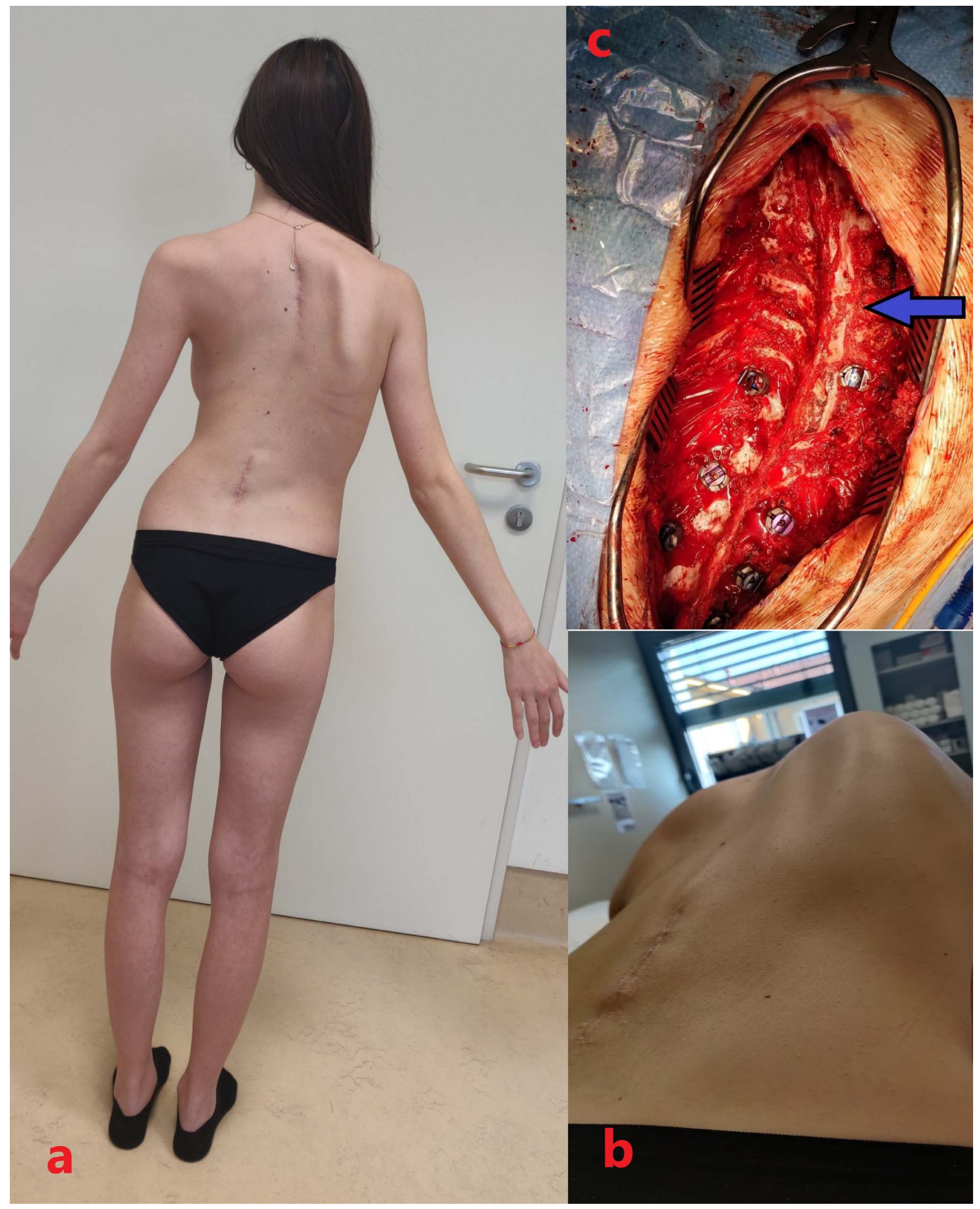

Figure 3. $2^{\circ}$ case. a) The clinical image, at 10 months after removal of Magec rods, shows the clear worsening, with an unbalanced trunk and shoulders. b) The clinical image, at 10 months after removal of Magec rods, points out a severe ribs hump (Adams test). c) The intraoperative picture, during the final instrumented fusion, shows an arthrodesis (blue arrow) on the convexity side of the thoracic curve, a sign of spontaneous autofusion. 


\section{REFERENCES}

1. Skaggs DL, Guillaume T, El-Hawary R, et al. Early onset scoliosis consensus statement: SRS Growing Spine Committee 2015. Spine Deform. 2015;3(2):107.

2. Lenke LG. Long-term effects of instrumented fusion in growing children. In: Akbarnia BA, Yazici M, Thompson GH, eds. The Growing Spine: Management of Spinal Disorders in Young Children. Berlin: Springer; 2016:535-545.

3. Kocyigit IA, Olgun ZD, Demirkiran $\mathrm{HG}$, et al. Graduation protocol after growing-rod treatment: removal of implants without new instrumentation is not a realistic approach. J Bone Joint Surg Am. 2017;99(18):1554-1564.

4. Cahill PJ, Marvil S, Cuddihy L, et al. Autofusion in the immature spine treated with growing rods. Spine (Phila Pa 1976). 2010;35(22):E1199-E1203.

5. Poe-Kochert C, Shannon C, Pawelek JB, et al. Final fusion after growing-rod treatment for early onset scoliosis: is it really final? J Bone Joint Surg Am. 2016;98(22):1913-1917.

6. Sawyer JR, Goes R, Flynn TS, et al. Complications and radiographic outcomes of posterior spinal fusion and observation in patients who have undergone distraction-based treatment for early onset scoliosis. Spine Deform. 2016;4:407-412.

7. Minkara A, Bainton N, Tanaka M, et al. High risk of mismatch between sanders and risser staging in adolescent idiopathic scoliosis: are we guiding treatment using the wrong classification? J Pediatr Orthop. 2020;40(2):60-64.
8. Jain A, Sponseller PD, Flynn JM, et al; Growing Spine Study Group. avoidance of "final" surgical fusion after growing-rod treatment for early-onset scoliosis. J Bone Joint Surg Am. 2016;98(13):1073-1078.

Disclosures and COI: The authors received no funding for this study and report no conflicts of interest.

Corresponding Author: Mauro Spina, MD, Department of Orthopedics and Traumatology Azienda Ospedaliera Universitaria Integrata of Verona, A. Piazzale A. Stefani n.1, 37126 Verona, Italy. Phone: 3495307080 - 0458122465; Fax: 0458123536; Email: spina.mauro@gmail.com.

Published 11 November 2020

This manuscript is generously published free of charge by ISASS, the International Society for the Advancement of Spine Surgery. Copyright (C) 2020 ISASS. To see more or order reprints or permissions, see http://ijssurgery.com. 